\begin{tabular}{c} 
journal homepage: http://ijiemjournal.uns.ac.rs/ \\
International Journal of Industrial \\
Engineering and Management \\
Volume $11 /$ No $1 /$ March $2020 / 19-30$ \\
\hline
\end{tabular}

Original research article

\title{
Testing vision picking technology in warehouse operations: Evidence from laboratory experiments
}

\author{
A. Gialos, V. Zeimpekis * \\ Department of Financial and Management Engineering, School of Engineering, \\ University of the Aegean, Chios, Greece
}

\section{A B STRACT}

Lately, the complexity of warehouse operations has increased significantly due to the increase of same-day deliveries, customer requests for frequent and low-volume orders as well as the need for faster response times. Although all warehouse processes are critical, order picking contributes significantly to the total operational warehouse costs and affects also customer service level. The aim of this paper is to present evidence from laboratory experiments that evaluate vision picking technology in both accuracy and time efficiency level. We adopt the Design of Experiments (DoE) methodologyin order to examine the impact of four parameters that affect the performance of the system. The results are encouraging showing the benefits that order pickers may have by adopting the proposed technology.

\author{
ARTICLE INFO
}

Article history:

Received August 31, 2019

Revised January 6, 2020

Accepted January 8, 2020

Published online February 3, 2020

Keywords:

Vision picking;

Wearable technology;

Logistics 4.0;

Smart glasses

* Corresponding author:

Vasileios Zeimpekis

vzeimp@fme.aegean.gr

\section{Introduction}

The need for improving warehouse processes has increased lately due to a new and disruptive logistics model that many companies have adopted that incorporates same-day deliveries, frequent and item-level orders, in order to keep minimum stock, as well as customized orders' fulfilment due to the increase of e-commerce sales channel [1,2,34].

Focusing on intralogistics, all warehouse processes such as receiving, put-away, replenishment, and packing, affect significantly the logistics cost, however the order picking process has a crucial impact on both logistics costs and customer service [1, 33]. For warehouses with manual systems, order picking is the most labour-intensive operation in warehouses and accounts for no less than $55 \%$ to $65 \%$ of the total operational warehouse costs [3], while for warehouses with automated systems, order picking is a very capital intensive operation due to the high investment cost that is required $[4,5,34]$. Indicative reasons for increased picking cost include travelling time among the aisles, no use of picking information systems, wrong warehouse layout design, as well as long waiting times in front of pick faces [6, 34]. Order picking is thus characterized by professionals as the highest priority process for productivity improvements [7].

The development of IT solutions during the last 
decades brought a considerable number of applications and systems in order-picking process such as voice and light picking [35]. Nevertheless, there is still need for higher productivity, efficiency and less operational cost.Vision picking through smart glasses seems to be a promising technology that can fulfil the aforementioned requirements in certain cases.

The Pick-by-Vision/Vision picking system, which uses wearable technology, embraces vision-guided technologies to produce a faster, hands-free solution for industrial environments [8]. This order picking system uses smart glasses to merge virtual images and information with an operator's surrounding environment. The operator wears the glasses, follows the commands given, and scans product barcodes all within the glasses' display. Pick-by-Vision systems can be supported by wearable AR or non-AR hardware platform such as Head Mounted Displays (HMDs) and Smart Glasses [8, 9]. Up to know a limited research on vision picking system performance is available and published, showing the need for investigating critical issues that deal with vision picking system design, development and testing. To this end, the scope of this paper is the evaluation of a proposed vision picking (VP) system via laboratory tests. Four parameters identified via a Systematic Literature Review (SLR) process and selected via an Analytical Hierarchy Process (AHP) methodology are investigated via a series of laboratory tests that are conducted by adopting the Design of Experiments (DoE) methodology. The proposed vision picking system is evaluated in terms of order picking completion time and accuracy.

The remainder of the paper is organised as follows. Initially a review is conducted in existing order picking technologies. Then the main factors that affect the performance of a vision picking system are presented followed by the design of experiment that was adopted for system testing. Subsequently, the results from the laboratory tests are presented and the paper concludes with useful insights from the tests performed as well as future research steps.

\section{Order picking technologies}

Due to the significance of order picking as a warehouse process, various studies have already been published that focus on the optimization of this process, drilling downon facility layout design, storage assignment, zoning, batching and routing methods, the number and size of orders, the types of functional areas, the selection of material handling equipment $[5,7,10]$, as well as the warehouse operating and routing policies (e.g.s-shape, return, midpoint, largest gap, combined, composite schemes, etc.) [34]. The latter are important parameters that have been considered for the selection and optimization of manual order picking systems. On the other hand, during the last decade, the adoption of automated order picking systems such AS/RS systems or Automated Guided Vehicles is another approach for increased productivity, cost savings, and errors reduction [11]. Nevertheless, the investment cost, the interrupting operation of the warehouse during the implementation period, and the loss of flexibility in the long term are some of the most common barriers for the development of automated or semi-automated technical solutions in order to support picking operations [12].

For picker-to-goods systems, the development of information technologies during the last decades has brought a remarkable number of ICT-based applications and technologies (e.g. Pick-by-Light Systems, Pick-by-Voice Systems, etc.) which support the picking process [13, 35]. The latter have managed to digitally transform the traditional order picking systems which are based on paper picking lists and increase the efficiency and productivity of pickers [1]. Nevertheless, recent trends in customer service such as the acceptance of late orders and the direct delivery/cross-docking within tight time windows have created a series of challenges for logistics companies that deal with the reduction of available time for order picking and increased errors in terms of order accuracy and completeness.

For that reason, a growing number of companies have turned their interest to digitalization by adopting logistics 4.0 technologies and smart applications along their business processes in order to handle the growing challenges of cost efficiency, flexibility, adaptability, stability, customer service, and sustainability [14, 33]. This emerging trend of automation coupled with the use of advanced Information Technology (IT) systems and smart applications provides a wide range of opportunities and benefits for the logistics sector $[15,16]$. Especially, in order picking process the use of vision picking through smart glasses can support both time efficiency and picking accuracy [17]. Vision picking is a promising order picking technology but is still at an early stage [18]. Thus, it is necessary to identify and investigate the key parameters that affect this technology. 


\section{Review of parameters that affect vision picking technology performance}

Based on the results of the Systematic Literature review (SLR) conducted, 20 parameters were identified which are classified into three main categories as depicted in Figure 1. The first category deals with the device design and development and includes fourteen (14) reviewed parameters. The second category comprises three (3) parameters which concern the testing of the performance of the vision picking technology in the industrial environment. Last but not least, the third category has to do with three (3) parameters which are used for the comparison of vision picking technology with other picking technologies in the industrial environment. Figure 2, shows the parameters for system parameterization (Category 1) that can be further classified into three different sub-categories. The first sub-category deals with the ergonomic aspects and involves four parameters (display type, interaction device, display holder and weight of equipment). The second focuses on visualization aspects and includes seven parameters (field of view, information mode, information availability, display view, existence of Augmented Reality and display settings) while the third sub-category is associated with technical aspects and encompasses four parameters (barcode type, scanning distance, battery life and existence of tracking system).

Category 2 (Parameters for operational performance) comprises three parameters namely: a) picking strategy (i.e. multiple order picking or discrete picking), b) Handling unit (i.e. item or box), and c) existence of confirmation (yes or no). Finally, Category 3 (Parameters for comparative assessment) deals with the comparative assessment of vision picking technology with other conventional order picking technologies in industrial environments. There are three key parameters which are: a) the number of orders, b) the lines per order, and c) the items per order line. In order to identify the most important parameters that affect a vision picking system, we designed a questionnaire and engaged 15 logistics managers to prioritize the parameters identified by the SLR. In order to do that, we adopted the Analytical Hierarchy Process (AHP).

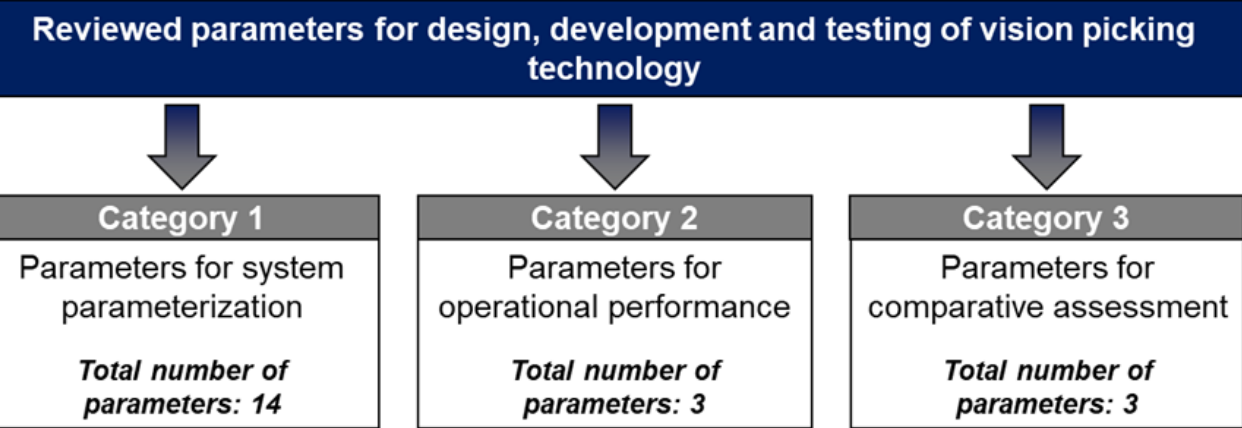

Figure 1. Classification schem

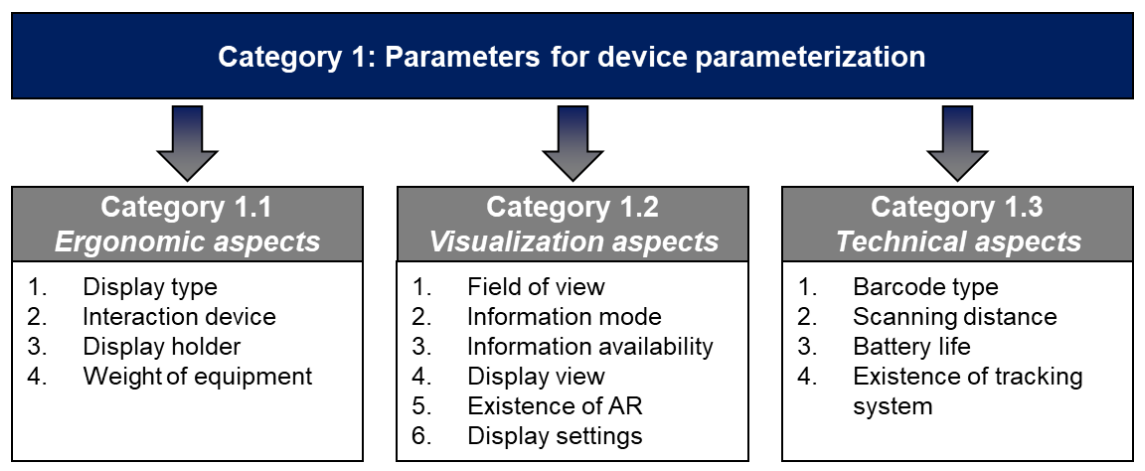

Figure 2. Classification of pa ameters for devise parameterization 
The AHP methodology is a decision support tool which compares criteria or alternatives with reference to specified criterion in pair wise-mode. In order to achieve this comparison, it is necessary to use a fundamental scale of numbers which has been proven in practice and validated. By using this fundamental scale of numbers, the individual preferences can be converted into a linear additive weight for each alternative [30]. The results of this methodology can be taken into account by decision makers in order to evaluate and rank the alternatives and make a proven choice. AHP methodology includes the following three steps [31]:

\section{- $\quad$ Step 1: Establish the hierarchy structure}

In this step the construction of hierarchy structure takes place. The first level of hierarchy deals with the goal of the analysis. The second level includes the criteria or dimensions of analysis while the last level focus on alternatives;

\section{- $\quad$ Step 2: Constructing the pair wise} comparison matrix

During the second step, a set of pairwise comparison matrices is constructed. Each element in an upper level is used to compare the elements in the level immediately below with respect to it. In order to make comparisons, it is necessary to be used a scale of numbers (from 1 to 9) [31] that indicates how many times more important or dominant one element is over another element with respect to the criterion or property with respect to which they are compared. The standard numeric scale used for AHP is from 1 to 9 scale which lies between "equal importance" to "extreme importance", the value 9 indicates that one factor is extremely less important than the other, while value 1 indicates equal importance;

\section{- $\quad$ Step 3:Calculate the consistency}

In the last step of the AHP methodology, the calculation of consistency takes place. More specifically, in order to confirm that the priority of elements is consistent, the consistency index (CI) for each matrix, as well as the Random Consistency index (RI) should be calculated. The interested reader may [32] for more details about the implementation steps of AHP methodology;
To this end, the AHP ranking as well as the experts' opinions were taken into consideration and four parameters were finally selected, namely: (a) display holder, (b) the field of view, (c) the barcode type, as well as (d) the existence of confirmation. The latter parameter was suggested by the logistics experts, (during the filling of questionnaire for the ranking of vision picking system design parameters) to be included in the Laboratory tests, since this parameter apart from the critical effects on operational performance, affects the acceptance of system by the end users.

The first parameter is the display type. According to the available equipment that can be used for vision picking [19], there are two different types of display holders. The first type is the glasses (Figure 3a), while the second type is the headbands (Figure 3b), which are worn on the head, using the suitable equipment [18]. Some of the most well-known glasses and headbands for vision picking are the followings: Google glasses, Vuzix M300, Epson Moverio BT-300, Microsoft HoloLens, RealWear HMT-1, etc. [20]. Both types of display holders have been evaluated in a series of tests and according to [18], they provide a hands-free solution for the execution of the order picking process. The type of holder together with the total weight of equipment can affect the performance of pickers and are responsible for a series of problems that pose various restrictions for pickers when wearing the equipment.

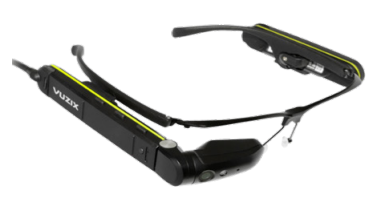

(a)

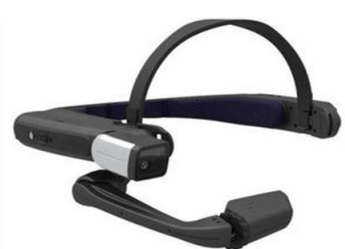

(b)
Figure 3. a) Vuzix M300 (Smart Glasses) and b) RealWear HMT-1 (Headbands)

The second parameter is the field of view and can be affected from the mounting options of the display. More specifically, the field of view is the area in which the pickers can see the content while wearing their glasses or headbands. According to [21], the full field of view of a human is $180^{\circ}$, however the use of vision picking equipment for the execution of order picking process reduces the field of view of pickers. Indeed, the display area of available glasses or 
headbands covers a field of view of $20^{\circ}$ to $90^{\circ}$ [20, 21]. To this point, it is worth mentioning that a significant number of vision picking devices has a really small field of view [19], and this fact creates multiple problems that deal with the performance and the safety of pickers when vision picking is adopted in industrial environments [22, 23]. On the other hand, the larger fields of view increase the satisfaction level of pickers [24] as well as task performance [25].

The third parameter is the barcode type. Based on the results of our literature review, there are two different types of barcodes. The first type is the 1D barcode while the second type deals with the $2 \mathrm{D}$ barcode ( $\mathrm{QR}$ code). More specifically, barcode labels are attached to items and racks and the pickers confirm their picks or their position by scanning the barcodes of items or racks [26]. According to [18], in most cases the use of barcodes and QR codes has dominated the logistics sector, but some other studies highlight the need for linking the order picking systems with automatic identification systems, such as RFID tags [27]. In our case we attached barcode labels on the racks of our laboratory in order to ensure that the pickers were in the right storage location to pick the right item. More specifically, the picker received picking and placement information via their display. Then they arrived in the suggested storage location, scanned the barcode of the rack and if the position was right the system provided more information for the picking process, otherwise the system informed the picker that their position is not the correct one.

The last parameter is the existence of pick confirmation during the order picking process. According to [36], during the order picking process there are two different types of confirmation. The first is the pick-from confirmation which is used to ensure that picking is performed from the right locations, while the second type focuses on the place-to confirmation which is used to ensure that the components are placed in the right tote (for the cases of multiple order picking - pick to cart). Based on the results of literature review, most studies use a confirmation system, in order to increase the accuracy as well as the quality of the process [36]. The confirmation of picks can be done with different ways. According to [20], an effective way for the picks confirmation is the scanning of items' QR codes with an external QR code reader, while [9] suggest the use of a RF scanner (reader can be handheld or worn as a glove or ring scanner). Also, $[8,17,22]$ mention that a voice confirmation is a reliable solution, while other studies assess the use of a confirmation button for the picks confirmation [26, 27]. On the other hand, according to [36], button presses are commonly used in association with light indicators in pick-by-lightsystems, while voice commands are typically used in pick-by-voice systems. To this end, in our laboratory tests, RFID technology (via RFID bracelet) was used for the picking confirmation, based on [17] and [35] recommendations. RFID scans, based on a technology that recently has emerged in applications that support picking activities, have shown promising potential in order picking process [36].

\section{Design of experiments}

In order to evaluate the performance of vision picking technology (in terms of order picking efficiency and accuracy), a series of experiments were performed. The Design of Experiment (DOE) technique was used. DOE studies the effect of a series of factors in a process or system and also assists to determine the best settings of these factors in order to improve the performance of process or system [28].

Figure 4, shows the input of our experiment, which includes the four parameters (factors) as presented above, and two (2) outputs which are: a) the order picking efficiency (i.e. order picking time) as well as b) the accuracy of the picker (i.e. number of picking

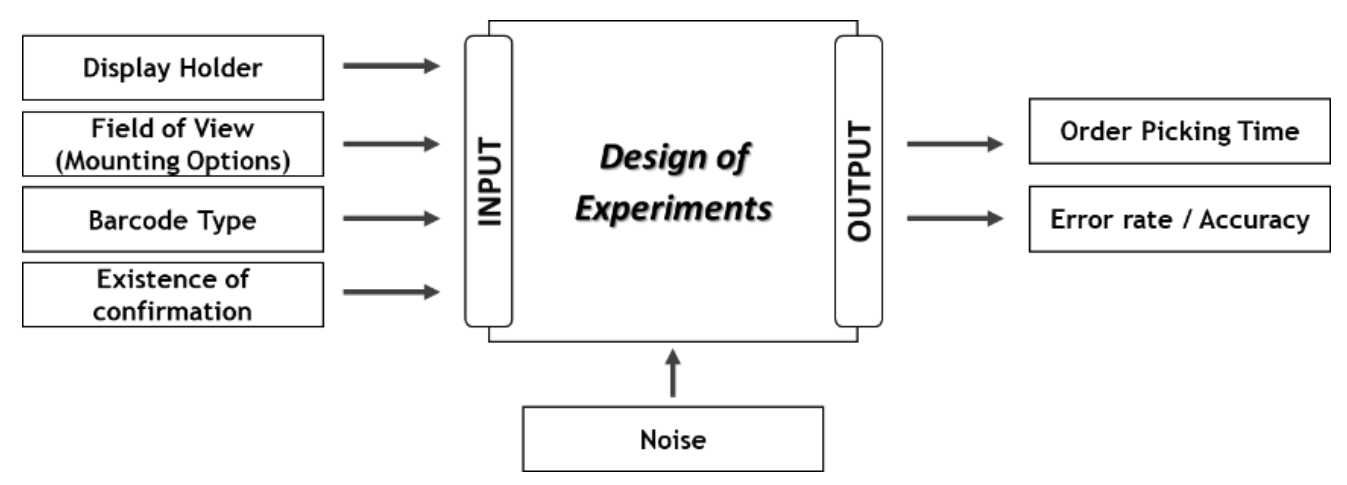

Figure 4. Model for order picking time and accuracy prediction 
mistakes). Moreover, a series of nuisance (noise) factors, that are taken into account include intra-logistics noise, lighting of the room, etc. Since the experimental procedure took place in a laboratory environment, the nuisance factors effects were not taken into consideration. Table 1, presents the selected factors as well as their corresponding levels which were used for the experiments. By taking into consideration the number of selected factors (4 factors in our case) as well as by considering [29] statement which argues that "when the number of factors is less than or equal to 4, the full factorial design is the most suitable choice", the full factorial design was selected for performing the experiments. A full factorial designed experiment consists of all possible combinations of levels for all factors and the total number of experiments for studying $\mathrm{k}$ factors at 2-levels is $2 \mathrm{k}[28,29]$. To this end a 24 full factorial design was prepared. By considering the 4 factors as well as their corresponding levels, there are fifteen degrees of freedom between sixteen (16) different configurations (Table 2).

Furthermore, the design of experiment that was developed included 5 replicates per run, so the total number of sample was $n=80$. It is also worth mentioning that the 80 runs were performed in random order. The randomization has been ensured through our Design of Experiments and the statistical processing of data made by Minitab software tool. Last but not least, in order to ensure that the normality of our results was satisfied, it was necessary to know the probability distribution of: a) order picking time and b) order picking accuracy. By adopting the Kolmogorov-Smirnov test, we checked the normality assumption and we confirmed that our data set (results of lab tests) were well-modelled by a normal distribution.

Table 1. Selected factor and their levels

\begin{tabular}{ccc}
\hline Factor & Level 1 & Level 2 \\
\hline Display holder & Glasses & Headbands \\
Field of View (Mounting Options) & Above of the line of sight & Below the line of sight \\
Barcode Type & D & 2D \\
Existence of confirmation & Yes & No \\
\hline
\end{tabular}

Table 2. The design matrix

\begin{tabular}{|c|c|c|c|c|}
\hline Run & Display Holder & $\begin{array}{c}\text { Field of View } \\
\text { (Mounting Options) }\end{array}$ & Barcode Type & Existence of confirmatio \\
\hline 1 & Glasses & Above of line of sight & 1D & Yes \\
\hline 2 & Glasses & Above of line of sight & $1 \mathrm{D}$ & No \\
\hline 3 & Glasses & Above of line of sight & $2 \mathrm{D}$ & Yes \\
\hline 4 & Glasses & Above of line of sight & $2 \mathrm{D}$ & No \\
\hline 5 & Glasses & Below of line of sight & $1 \mathrm{D}$ & Yes \\
\hline 6 & Glasses & Below of line of sight & $1 \mathrm{D}$ & No \\
\hline 7 & Glasses & Below of line of sight & $2 \mathrm{D}$ & Yes \\
\hline 8 & Glasses & Below of line of sight & $2 \mathrm{D}$ & No \\
\hline 9 & Headbands & Above of line of sight & $1 \mathrm{D}$ & Yes \\
\hline 10 & Headbands & Above of line of sight & $1 \mathrm{D}$ & No \\
\hline 11 & Headbands & Above of line of sight & $2 \mathrm{D}$ & Yes \\
\hline 12 & Headbands & Above of line of sight & $2 \mathrm{D}$ & No \\
\hline 13 & Headbands & Below of line of sight & 1D & Yes \\
\hline 14 & Headbands & Below of line of sight & 1D & No \\
\hline 15 & Headbands & Below of line of sight & $2 \mathrm{D}$ & Yes \\
\hline 16 & Headbands & Below of line of sight & $2 \mathrm{D}$ & No \\
\hline
\end{tabular}




\section{Laboratory test results}

\subsection{Subjects features}

A total of 16 subjects took part in laboratory tests: nine (9) male and seven (7) female, all in the ages between 23 and 58 years. The average age of participants was 35.83 (standard deviation 10.35). Fifteen (15) subjects were right-eye dominant and one (1) is left-eye dominant eye. Four (4) of them used prescription glasses. Subjects without previous experience of order picking process were selected to avoid previous experience biasing the results of our experiments. To compensate the lack of experience and minimize learning effects, the subjects attended a training session, where each of the subjects executed a series of orders' picking in the laboratory, making themselves familiar with vision picking technology. All subjects were native Greek speakers, so all instructions and survey instruments were provided to the subjects in Greek during this study. All the data for this study were collected via personal questionnaires.

\subsection{Experimental setup and equipment}

The testing and evaluation of vision picking technology took place in a dense-picking laboratory environment which was hosted at our partner's headquarters (Mantis Informatics S.A.) in Athens.

Our laboratory environment (Figure 5) consisted of 24 pick bins divided between two shelving units (light duty shelving system), A, and B. Each shelving unit had four rows and three columns and each pick bin contained $10-15$ items. The order cart, which was used during the multiple order picking, had three storage levels and each level hosted two plastic bins (totes). To this end, each subject could pick 6 orders, simultaneously (each plastic bin was assigned to one order). The subject had to finish 5 picking lists using vision picking technology. Each picking list contained six orders (6) while each order included an average of seven (7) order lines. The average number of items per order line was two (2). The items were boxes in different sizes and with different weights, while all items could be handled with one hand. All the experiments were accomplished by using specialized equipment. More specifically, two different types of head-mounted displays (HMDs) were used. The first HMD was the VUZIX M300 and the second HMD is the RealWear HMT-1

\subsection{Research hypotheses}

For the evaluation of vision picking technology we measured outputs that affect the productivity, performance as well as the customer service level. The first output was the order picking time and the second was the accuracy of order picking process. The order picking time was measured with a common stopwatch, while the accuracy was calculated by taking into consideration the error rate. The error rate was counted manually after the completion of order picking process. For these outputs as well for the four factors that have been taken into account for the evaluation of vision picking technology, certain null hypotheses were introduced. As it can be seen below, there were four null hypotheses for the order picking time and four null hypotheses for the accuracy.

The first null hypothesis $\left(\mathrm{H}_{0,1}\right)$ states that the order picking time is the same when either glasses or headbands are used:

$$
\mathrm{H}_{0,1}: \mathrm{t}_{\text {glasses }}=\mathrm{t}_{\text {headbands }}
$$

The second null hypothesis $\left(\mathrm{H}_{0,2}\right)$ states that the order picking time is equal when either the display was above of line of sight or the display was below of line of sight:

$$
\mathrm{H}_{0,2}: \mathrm{t}_{\text {above_of_LS }}=\mathrm{t}_{\text {below_of_LS }}
$$

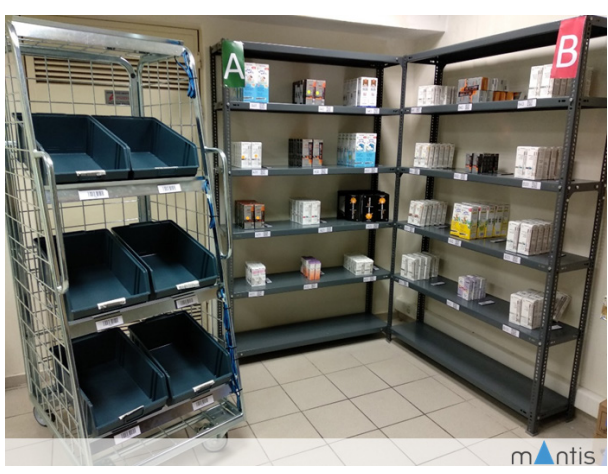

(a)

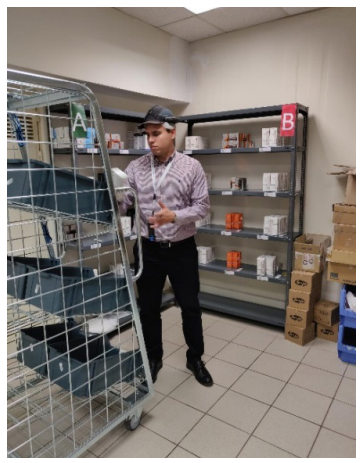

(b)

Figure 5. a) Dense-picking laboratory (Mantis Informatics S.A.) b) Photos from the execution of laboratory tests 
The third null hypothesis $\left(\mathrm{H}_{0,3}\right)$ states that the order picking time is equal either when the barcode type was $1 \mathrm{D}$ or the barcode type was $2 \mathrm{D}$ :

$$
\mathrm{H}_{0,3}: \mathrm{t}_{\text {barcode_1D }}=\mathrm{t}_{\text {barcode_2D }}
$$

The fourth null hypothesis $\left(\mathrm{H}_{0,4}\right)$ states that the order picking time is equal either when there was confirmation during the order picking process or not:

$$
\mathrm{H}_{0,4}: \mathrm{t}_{\text {confirmation_yes }}=\mathrm{t}_{\text {confirmation_no }}
$$

The fifth null hypothesis $\left(\mathrm{H}_{0,5}\right)$ states that the accuracy when glasses were used was the same with the accuracy when headbands were used:

$$
\mathrm{H}_{0,5}: \mathrm{t}_{\text {glasses }}=\mathrm{t}_{\text {headband }}
$$

The sixth null hypothesis $\left(\mathrm{H}_{0,6}\right)$ states that the accuracy when the display was above of line of sight was equal with the accuracy when the display was below of line of sight:

$$
\mathrm{H}_{0,6}: \mathrm{t}_{\text {above_of_LS }}=\mathrm{t}_{\text {below_of_LS }}
$$

The seventh null hypothesis $\left(\mathrm{H}_{0,7}\right)$ states that the accuracy when the barcode type was $1 \mathrm{D}$ was equal with the accuracy when the barcode type was 2D:

$$
\mathrm{H}_{0,7}: \mathrm{t}_{\text {barcode_1D }}=\mathrm{t}_{\text {barcode_2D }}
$$

The eighth null hypothesis $\left(\mathrm{H}_{0,8}\right)$ states that the accuracy is equal either when there was confirmation during the order picking process or not:

$$
\mathrm{H}_{0,8}: \mathrm{t}_{\text {confirmation_yes }}=\mathrm{t}_{\text {confirmation_no }}
$$

Following to the data collection, a quantitative analysis of the order picking time and accuracy was performed by using ANOVA. The results showed that there were not statistically significant differences for the cases $\mathrm{H} 0,1, \mathrm{H} 0,2, \mathrm{H} 0,3, \mathrm{H} 0,5, \mathrm{H} 0,6, \mathrm{H} 0,7$, $\mathrm{H} 0,8$, and as a result the null hypothesis was not rejected. On the other hand, for the H0,4case, the results showed that there was statistically significant difference and the null hypothesis was rejected (i.e. the alternative hypothesis was accepted). To this point, it is important to mention that the level of significance which was used for the analysis was $5 \%(\mathrm{a}=0.05)$. Furthermore, to ensure that the normality of our results was satisfied, it was necessary to know the probability distribution of: a) order picking time and, b) order picking accuracy. By adopting the Kolmogorov-Smirnov test, we checked the normality assumption and confirmed that the data set (results of lab tests) were well-modelled by a normal distribution.

\subsection{Results: Order picking time}

The Design of Experiment-ANOVA results- (16 test cases with 5 repetitions each, i.e. 80 tests in total) for pick-to-cart case (multi-order picking - 6 orders simultaneously), showed that only for the parameter "existence of confirmation" a statistically significant difference existed $(p \leq 0.05)$ in terms of order picking time. More specifically, the use of vision picking technology with confirmation step increases the job completion time at almost $20 \%$, when compared to the use of vision picking technology with no confirmation step (see results in Table 3).

Apart from the statistically significant configuration, figure 6 presents the interaction plot for all the configurations which were evaluated during the Lab tests, in terms of order picking efficiency. The detailed results of all configurations in terms of order picking time are presented in Table 4.

Table 3. Results of order picking time for the 2 levels of factor "existence of confirmation

\begin{tabular}{cc}
\hline Existence of confirmatio & Mean Picking Time \\
\hline Yes & 310 Second \\
No & 249 Second
\end{tabular}

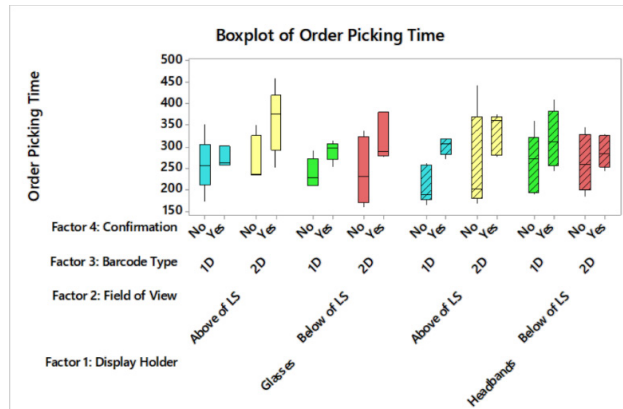

Figure 6. Interaction effects of Displ y Holder (glasses vs. headbands), Field of view / mounting options (Above of line of sight vs below of line of sight), Barcode type (1D vs. 2D) and existence of confirmati $n$ (yes vs. no) on order picking time 
Table 4. Results of interaction effects in terms of o der picking time

\begin{tabular}{|c|c|c|c|c|c|c|c|c|c|c|c|c|c|c|c|c|}
\hline Factor 1 & Glasses & Glasses & Glasses & Glasses & Glasses & Glasses & Glasses & Glasses & $\begin{array}{l}\text { Head- } \\
\text { bands }\end{array}$ & $\begin{array}{l}\text { Head- } \\
\text { bands }\end{array}$ & $\begin{array}{l}\text { Head- } \\
\text { bands }\end{array}$ & $\begin{array}{l}\text { Head- } \\
\text { bands }\end{array}$ & $\begin{array}{l}\text { Head- } \\
\text { bands }\end{array}$ & $\begin{array}{l}\text { Head- } \\
\text { bands }\end{array}$ & $\begin{array}{l}\text { Head- } \\
\text { bands }\end{array}$ & $\begin{array}{l}\text { Head- } \\
\text { bands }\end{array}$ \\
\hline Factor 2 & $\begin{array}{c}\text { Above } \\
\text { of } \\
\text { LS }\end{array}$ & $\begin{array}{c}\text { Above } \\
\text { of } \\
\text { LS }\end{array}$ & $\begin{array}{c}\text { Above } \\
\text { of } \\
\text { LS }\end{array}$ & $\begin{array}{c}\text { Above } \\
\text { of } \\
\text { LS }\end{array}$ & $\begin{array}{l}\text { Below } \\
\text { of } \\
\text { LS }\end{array}$ & $\begin{array}{l}\text { Below } \\
\text { of } \\
\text { LS }\end{array}$ & $\begin{array}{l}\text { Below } \\
\text { of } \\
\text { LS }\end{array}$ & $\begin{array}{c}\text { Below } \\
\text { of } \\
\text { LS }\end{array}$ & $\begin{array}{c}\text { Above } \\
\text { of } \\
\text { LS }\end{array}$ & $\begin{array}{c}\text { Above } \\
\text { of } \\
\text { LS }\end{array}$ & $\begin{array}{c}\text { Above } \\
\text { of } \\
\text { LS }\end{array}$ & $\begin{array}{c}\text { Above } \\
\text { of } \\
\text { LS }\end{array}$ & $\begin{array}{c}\text { Below } \\
\text { of } \\
\text { LS }\end{array}$ & $\begin{array}{c}\text { Below } \\
\text { of } \\
\text { LS }\end{array}$ & $\begin{array}{c}\text { Below } \\
\text { of } \\
\text { LS }\end{array}$ & $\begin{array}{l}\text { Below } \\
\text { of } \\
\text { LS }\end{array}$ \\
\hline Factor 3 & 1D & 1D & $2 \mathrm{D}$ & $2 \mathrm{D}$ & 1D & 1D & $2 \mathrm{D}$ & $2 \mathrm{D}$ & 1D & $1 \mathrm{D}$ & $2 \mathrm{D}$ & $2 \mathrm{D}$ & 1D & 1D & $2 \mathrm{D}$ & $2 \mathrm{D}$ \\
\hline Factor 4 & No & Yes & No & Yes & No & Yes & No & Yes & No & Yes & No & Yes & No & Yes & No & Yes \\
\hline $\begin{array}{c}\mathrm{Q1} \\
\text { (second) }\end{array}$ & 209 & 256.5 & 232 & 292 & 208.5 & 269.5 & 169 & 277.5 & 173.5 & 281 & 178.5 & 279 & 192 & 254 & 197.5 & 251 \\
\hline $\begin{array}{l}\text { Median } \\
\text { (second) }\end{array}$ & 253 & 260 & 235 & 375 & 227 & 295 & 228 & 287 & 188 & 306 & 200 & 360 & 270 & 310 & 258 & 283 \\
\hline $\begin{array}{c}\text { Q3 } \\
\text { (second) }\end{array}$ & 305 & 300.5 & 326 & 418.5 & 271.5 & 306 & 322 & 380 & 256.5 & 316.5 & 370 & 369.5 & 320 & 381 & 326.5 & 325 \\
\hline
\end{tabular}

Taking into consideration the figure and table above, it can be seen that the best configuration, when using the median for comparison, in terms of order picking time embraces headbands, the display to be above of line of sight, 1D barcode and no confirmation step $(\mathrm{Q} 1=173.5$ seconds, Median $=188$ seconds, $\mathrm{Q} 3=256.5$ seconds). The second best configuration includes headbands, the display to be above of line of sight, 2D barcode and no confirmation step $(\mathrm{Q} 1=178.5$ seconds, Median $=200$ seconds, Q3 $=370$ seconds). On the other hand, the configuration with the highest order picking time contains glasses, the display to be above of line of sight, 2D barcode and confirmation step (Q1 $=292$ seconds, Median $=375$ seconds, $Q 3=418.5$ seconds

\subsection{Results: Accuracy}

In terms of order picking accuracy, the ANOVA results showed that only the 2-way interaction "Field of View* Existence of confirmation" was statistically significant $(\mathrm{p} \leq 0.05)$. Thus, it was concluded that the accuracy of vision picking technology can be significantly affected, only by the configuration "Field of View ${ }^{*}$ Existence of confirmation" since all the other configurations did not provide statistically signif- icant differences in terms of order picking accuracy.

By, taking into account the results of statistical analysis, the interaction between the "Field of View" and the "Existence of confirmation" shows that when the existence of confirmation is "Yes" and the field of view (mounting options) is "Below line of sight", the Vision picking process can be accomplished more accurately when compared with the other configurations shown in Table 5 .

Apart from the statistically significant configurations, figure 7 presents the interaction plot for all the configurations which are evaluated during the Lab tests, in terms of order picking accuracy. The detailed results of all configurations in terms of order picking time are presented in Table 6 .

Table 5. Results of interaction plot of Field of view / mounting options (Above of line of sight vs. below of line of sight) and existence of confirmation ( es vs. no) on order picking accuracy

\begin{tabular}{ccc}
\hline Field of View & $\begin{array}{c}\text { Existence of confi - } \\
\text { mation }\end{array}$ & Mean of Accuracy \\
\hline Below line of sight & Yes & $99.3 \%$ \\
Above line of sight & No & $98.5 \%$ \\
Above line of sight & Yes & $98.1 \%$ \\
Below line of sight & No & $96.7 \%$
\end{tabular}

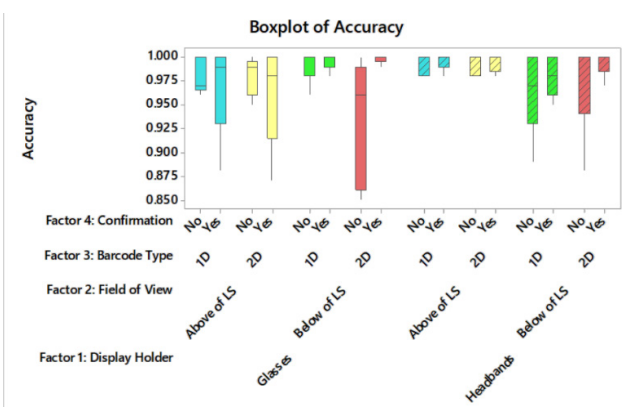

Figure 7. Interaction effects of Displ y Holder (glasses vs. headbands), Field of view / mounting options (Above of line of sight vs. below of line of sight), Barcode type (1D vs. 2D) and existence of confirmati n (yes vs. no) on order picking accuracy 
Table 6. Results of interaction effects in terms of o der picking accuracy

\begin{tabular}{|c|c|c|c|c|c|c|c|c|c|c|c|c|c|c|c|c|}
\hline Factor 1 & Glasses & Glasses & Glasses & Glasses & Glasses & Glasses & Glasses & Glasses & $\begin{array}{c}\text { Head- } \\
\text { bands }\end{array}$ & $\begin{array}{c}\text { Head- } \\
\text { bands }\end{array}$ & $\begin{array}{c}\text { Head- } \\
\text { bands }\end{array}$ & $\begin{array}{c}\text { Head- } \\
\text { bands }\end{array}$ & $\begin{array}{c}\text { Head- } \\
\text { bands }\end{array}$ & $\begin{array}{c}\text { Head- } \\
\text { bands }\end{array}$ & $\begin{array}{c}\text { Head- } \\
\text { bands }\end{array}$ & $\begin{array}{c}\text { Head- } \\
\text { bands }\end{array}$ \\
\hline Factor 2 & $\begin{array}{c}\text { Above } \\
\text { of } \\
\text { LS }\end{array}$ & $\begin{array}{c}\text { Above } \\
\text { of } \\
\text { LS }\end{array}$ & $\begin{array}{c}\text { Above } \\
\text { of } \\
\text { LS }\end{array}$ & $\begin{array}{c}\text { Above } \\
\text { of } \\
\text { LS }\end{array}$ & $\begin{array}{c}\text { Below } \\
\text { of } \\
\text { LS }\end{array}$ & $\begin{array}{c}\text { Below } \\
\text { of } \\
\text { LS }\end{array}$ & $\begin{array}{c}\text { Below } \\
\text { of } \\
\text { LS }\end{array}$ & $\begin{array}{c}\text { Below } \\
\text { of } \\
\text { LS }\end{array}$ & $\begin{array}{c}\text { Above } \\
\text { of } \\
\text { LS }\end{array}$ & $\begin{array}{c}\text { Above } \\
\text { of } \\
\text { LS }\end{array}$ & $\begin{array}{c}\text { Above } \\
\text { of } \\
\text { LS }\end{array}$ & $\begin{array}{c}\text { Above } \\
\text { of } \\
\text { LS }\end{array}$ & $\begin{array}{c}\text { Below } \\
\text { of } \\
\text { LS }\end{array}$ & $\begin{array}{c}\text { Below } \\
\text { of } \\
\text { LS }\end{array}$ & $\begin{array}{c}\text { Below } \\
\text { of } \\
\text { LS }\end{array}$ & $\begin{array}{c}\text { Below } \\
\text { of } \\
\text { LS }\end{array}$ \\
\hline Factor 3 & 1D & 1D & 2D & 2D & 1D & 1D & 2D & 2D & 1D & 1D & 2D & 2D & 1D & 1D & 2D & 2D \\
\hline Factor 4 & No & Yes & No & Yes & No & Yes & No & Yes & No & Yes & No & Yes & No & Yes & No & Yes \\
\hline $\begin{array}{c}\text { Q1 } \\
\text { (second) }\end{array}$ & 0.965 & 0.93 & 0.96 & 0.915 & 0.98 & 0.99 & 0.86 & 0.995 & 0.98 & 0.99 & 0.98 & 0.985 & 0.93 & 0.96 & 0.94 & 0.985 \\
\hline $\begin{array}{c}\text { Median } \\
\text { (second) }\end{array}$ & 0.97 & 0.99 & 0.99 & 0.98 & 1 & 1 & 0.96 & 1 & 0.98 & 1 & 1 & 1 & 0.97 & 0.98 & 1 \\
\hline $\begin{array}{c}\text { Q3 } \\
\text { (second) }\end{array}$ & 1 & 1 & 0.995 & 1 & 1 & 1 & 0.99 & 1 & 1 & 1 & 1 & 1 & 1 & 1 & 1 \\
\hline
\end{tabular}

As it can be seen from the figure and table above, the best configuration, when using the median for comparison, with the highest accuracy level embraces glasses, the display to be below of line of sight, 2D barcode and existence confirmation step $(\mathrm{Q} 1=$ 0.995 , Median $=1, \mathrm{Q} 3=1$ ), while the configuration with the lowest accuracy level includes glasses, the display to be above of line of sight, 2D barcode and no confirmation step $(\mathrm{Q} 1=0.96$, Median $=0.99$, Q3 $=0.995)$. Based on the results which are presented below, it is worth mentioning that the error rate is small, almost in all configurations and there is no factor that significantly affects the accuracy of the system.

\section{Conclusions and future steps}

This paperevaluated a proposed vision picking (VP) system for collection of products in item-level via laboratory tests. Four parameters identified via a Systematic Literature Review (SLR) process and selected via an Analytical Hierarchy Process (AHP) methodology were investigated via a series of laboratory tests that were conducted by adopting the Design of Experiments (DoE) methodology.

The laboratory setup which was developed in cooperation with a Greek IT company (Mantis Informatics S.A.),consisted of 24 pick bins divided between two shelving units. Each shelving unit had four rows and three columns and each pick bin contained 10 - 15 items. The order cart, which was used during the multiple order picking, had three storage levels and each level hosted two plastic bins (totes). Two different types of head-mounted displays (HMDs) were used. The first HMD was the VUZIX M300 and the second HMD is the RealWear HMT-1.
Eighty (80) tests were conducted in order to identify the optimal setup of the proposed vision picking system both in terms of order picking efficiency and accuracy. The results revealed that in terms of order picking efficiency (i.e. order picking time), the best configuration embraces headbands, the display to be above of line of sight, 1D barcode and no confirmation step, while in terms of accuracy the best configuration contains glasses, the display to be below of line of sight, 2D barcode and existence confirmation step. These results are encouraging showing the merit of the proposed system. These results also support both system designers as well as end-users that are interested in adopting such technology.

We intend to further continue our research by testing further parameters in lab environment in order to investigate their impact in order picking accuracy and efficiency. Subsequently, we intend to test the proposed system in real-life environment (field tests) in order to make a comparative assessment with other order picking systems such as RF-scanners, and voice picking.

\section{Acknowledgements}

The authors are very grateful to Mantis Informatics S.A. and especially to Mr. Nikolaos Arachovas, Mrs. Evanggelia Dovletoglou and Mr. Nikolaos Panagiotopoulos for their valuable support and contribution during the design and testing of the proposed system. We would like also to take this opportunity to thank also all the participants that took part in this experiment and gave us valuable feedback for optimizing the proposed system. 


\section{Funding}

This research did not receive any specific grant from funding agencies in the public, commercial, or not-for-profit sectors.

\section{References}

[1] Marchet, G.Melacini, M. and Perotti, S. (2014), "Investigating order picking system adoption: a case-study-based approach," International Journal of Logistics Research and Applications, Vol. 18, No. 1, pp. 82-98, doi:10.1080/13675567.2014.945400.

[2] Lu, W. McFarlane, D.Giannikas V., and Zhang, Q. (2016), "An algorithm for dynamic order-picking in warehouse operations," European Journal of Operational Research, Vol.248, No. 1, pp. 107-122, doi:10.1016/j.ejor.2015.06.074.

[3] Theys, C.Bräysy, O.Dullaert, W. and Raa, B. (2010), "Using a TSP heuristic for routing order pickers in warehouses," European Journal of Operational Research, Vol. 200, No. 3, pp. 755-763, doi:10.1016/j.ejor.2009.01.036.

[4] Tompkins, J.A. White, J.A. Bozer, Y.A. and Tanchoco, J.M.A. (2011),"Facilities planning - 4th edition," International Journal of Production Research, vol. 49, no. 24, pp.7519-7520, doi:10.1080/00207543.2011.563164.

[5] Chen, F. Wang, H. Xie, Y. and Qi, C. (2014), "An ACO-based online routing method for multiple order pickers with congestion consideration in warehouse," Journal of Intelligent Manufacturing, Vol. 27, No. 2, pp. 389-408, doi:10.1007/s10845-014-0871-1.

[6] Richards, G. (2014), "Warehouse Management: A complete Guide to Improving Efficiency and Minimizing Costs in the Modern Warehouse," 2nd edition, UK Kogan Page, ISBN 978-0749469344.

[7] de Koster, R. Le-Duc, T. and Roodbergen, K.J. (2007), "Design and control of warehouse order picking: A literature review," European Journal of Operational Research, Vol. 182, no. 2, pp. 481-501, doi:10.1016/j.ejor.2006.07.009.

[8] Schwerdtfeger, B. Reif, R. Günthner, W.A. Klinker, G. Hamacher, D. Schega, L. and Böckelmann, I. (2009) "Pick-by-Vision: A first stress test," in Science and Technology Proceedings - IEEE 2009 International Symposium on Mixed and Augmented Reality (ISMAR 2009), Orlando, FL, USA, doi:10.1109/ISMAR .2009 .5336484 .

[9] Weaver, K.A. Baumann, H.Starner, T. Iben, H.and Lawo, M. (2010), "An empirical task analysis of warehouse order picking using head-mounted displays," in Proceedings of the SIGCHI Conference on Human Factors in Computing Systems (CHI 2010), Atlanta, Georgia, USA, doi:10.1145/1753326.1753580.

[10] Dallari, F. Marchet, G. and Melacini, M. (2009), "Design of order picking system," International Journal of Advanced Manufacturing Technology, Vol. 42, No. 1-2, pp.1-12, doi:10.1007/s00170-008-1571-9.

[11] Hou, J.L., Wu, N., and Wu, Y.J. (2009), "A job assignment model for conveyor-aided picking system," Computers and Industrial Engineering, Vol. 56, No. 4, pp. 1254-1264, doi:10.1016/j.cie.2008.07.017.

[12] Hackman, S.T. Frazelle, E.H. Griffin, P.M. Griffin, S.O. and Vlasta, D.A. (2001), "Benchmarking Warehousing and Distribution Operations: An Input-Output Approach,” Journal of Productivity Analysis, Vol. 16, No. 1, pp. 79-100, doi:10.1023/A:1011155320454.

[13] van Gils, T Ramaekers,K. Caris, A. de Koster, R.B.M.
(2018), "Designing efficient order picking systems by combining planning problems: State-of-the-art classification and review," European Journal of Operational Research, Vol. 267, No. 1, pp. 1-15, doi:10.1016/j.ejor.2017.09.002.

[14] Wang, S. Wan, J. Li, D. and Zhang, C. (2016), "Im plementing Smart Factory of Industrie 4.0: An Out look," International Journal of Distributed Sensor Networks, Vol 2016, No. 1, pp. 1-11, doi:10.1155/2016/3159805.

[15] Olivares, V. Cordova, F. Sepúlveda, J.M. and Derpich, I. (2015), "Modeling internal logistics by using drones on the stage of assembly of products," Procedia Computer Science, Vol. 55, pp 1240-1249, doi:10.1016/j. procs.2015.07.132.

[16] Hofmann, E. and Rüsch, M. (2017), "Industry 4.0 and the current status as well as future prospects on logistics," Computers in Industry, Vol. 89, pp.23-34, doi:10.1016/j.compind.2017.04.002.

[17] Hanson, R. Falkenström, W. and Miettinen, M. (2017), "Augmented reality as a means of conveying picking information in kit preparation for mixed-model assembly," Computers and Industrial Engineering, Vol. 113, pp. 570-575, doi:10.1016/j.cie.2017.09.048.

[18] Stoltz, M.H. Giannikas, V. McFarlane, D. Strachan, Um, J. J. and Srinivasan, R. (2017), "Augmented Reality in Warehouse Operations: Opportunities and Barriers," IFAC-PapersOnLine, Vol. 50, No. 1, pp. 1297912984, doi:10.1016/j.ifacol.2017.08.1807.

[19] Syberfeldt, A. Danielsson, O. and Gustavsson, P. (2018), "Augmented Reality Smart Glasses in the Smart Factory: Product Evaluation Guidelines and Review of Available Products," IEEE Access, Vol. 5, pp. 9118-9130, doi:10.1109/ACCESS.2017.2703952.

[20] Bräuer, P. and Mazarakis, A. (2018), "AR in order-picking - experimental evidence with Microsoft HoloLens," Mensch Und Computer, pp. 361-368, Dresden, Germany, doi:10.18420/muc2018-ws07-0463.

[21] Renner, P. and Pfeiffer, T. (2017), “Augmented Reality Assistance in the Central Field-of-View Outperforms Peripheral Displays for Order Picking: Results from a Virtual Reality Simulation Study," Adjunct Proceedings of the 2017 IEEE International Symposium on Mixed and Augmented Reality, ISMARAdjunct 2017, Nantes, France, doi:10.1109/ISMAR-Adjunct.2017.59.

[22] Reif, R. Günthner, W.A. Schwerdtfeger, B. and Klinker G. (2010), "Evaluation of an augmented reality supported picking system under practical conditions," Computer Graphics Forum, Vol. 29, No. 1, pp. 2-12, doi:10.1111/j.1467-8659.2009.01538.x.

[23] Kim, S. Nussbaum, M.A. and Gabbard, J.L. (2019), "Influences of augmented reality head-worn display type and user interface design on performance and usability in simulated warehouse order picking," Applied Ergonomics, Vol. 74, pp.186-193, doi:10.1016/j.apergo.2018.08.026.

[24] Ok, A.E. Basoglu, N.A. and Daim, T. (2015), "Exploring the design factors of smart glasses," in 2015 Portland International Conference on Management of Engineering and Technology (PICMET), Portland, OR, USA, doi:10.1109/PICMET.2015.7273236.

[25] Kishishita, N. Kiyokawa, K. Orlosky,J. Mashita, T. Takemura, H. and Kruijff, E. (2014), "Analysing the effects of a wide field of view augmented reality display on search performance in divided attention tasks," in 2014 IEEE International Symposium on Mixed and Augmented Reality - Science and Technology (ISMAR), Munich, Germany, doi:10.1109/ISMAR.2014.6948425.

[26] Baumann, H. Starner, T. Iben, H. Lewandowski, A. and 
Zschaler, P. (2011), "Evaluation of graphical user-interfaces for order picking using head-mounted displays," Proceedings of the 13th International Conference on Multimodal Interfaces - ICMI '11, Alicante, Spain, pp. 377-384, doi:10.1145/2070481.2070553.

[27] Krajcovic, M. Gabajova, G. and Micieta, B. (2014), "Order picking using augmented reality," Communications-Scientific Letters of the University of Zilina, Vol. 16, No. 3A, pp. 106-111.

[28] Montgomery, D.C. (2012), "Design and Analysis of Experiments," 5th Edition, New Jersey, USA Willey.

[29] Antony, J. (2014), "Design of Experiments for Engineers and Scientists," Design of Experiments for Engineers and Scientists, 2nd Edition, Elsevier, doi:10.1016/C2012-0-03558-2.

[30] Luthra, S. Garg, D. and Haleem, A. (2013), "Identifying and ranking of strategies to implement green supply chain management in Indian manufacturing industry using analytical hierarchy process," Journal of Industrial Engineering and Management, Vol. 6, No. 4, pp. 930-962, doi:10.3926/jiem.693.

[31] Saaty, T. L. (2008), "Decision making with the analytic hierarchy process," International Journal of Services Sciences,Vol. 1, No. 1, pp. 83-98, doi:10.1504/ijssci.2008.017590.

[32] Saaty, R.W. (1979), "The analytic hierarchy process-what it is and how it is used,", Mathematical Modelling, Vol. 9, No. 3-5, pp. 161-176, doi:10.1016/0270-0255(87)90473-8.

[33] Krowas, K. and Riedel R. (2019), "Planning Guideline and Maturity Model for Intra-logistics 4.0 in SME," in Ameri, F. Stecke, K. von Cieminski, G. and Kiritsis, D. (eds) Advances in Production Management Systems. Towards Smart Production Management Systems, APMS 2019. IFIP Advances in Information and Communication Technology, Vol. 567, Springer, Cham.

[34] Cano, J.A. Correa-Espinal, A.A. and Gómez-Montoya, R.A. (2017), "An evaluation of picking routing policies to improve warehouse efficiency," International Journal of Industrial Engineering and Management, Vol. 8,No. 4, pp. 229-238.

[35] Fager, P. Hanson, R. Medbo, L. and Johansson, M.I. (2019), "Kit preparation for mixed model assembly - Efficiency impact of the picking information system," Computers \& Industrial Engineering, Vol. 129, pp. 169-178, doi: 10.1016/j.cie.2019.01.034.

[36] Fager, P. (2019), "Kit preparation for mixed-model assembly: efficiency impact of confirmation methods," Industrial Management \& Data Systems, Vol. 119,No. 3, pp. 547-560, doi:10.1108/IMDS-07-2018-0287. 